\title{
Familial streptomycin ototoxicity in a South African family: a mitochondrial disorder
}

Jessica C Gardner, Rene Goliath, Denis Viljoen, Sean Sellars, Gino Cortopassi, Tim Hutchin, Jacquie Greenberg, Peter Beighton
MRC Unit for Medical Genetics and Department of Human Genetics, University of Cape Town Medical School and Groote Schuur Hospital, Observatory 7925, South Africa J C Gardner R Goliath

$D$ Viljoen

J Greenberg

P Beighton

Department of Otolaryngology, University of Cape Town Medical School and Groote Schuur Hospital, Observatory 7925, South Africa S Sellars

Department of Molecular Biosciences, University of California, Davis, CA 95616, USA G Cortopassi T Hutchin

Correspondence to: Dr Gardner.

Received 10 April 1996 Revised version accepted for publication 25 June 1997

\begin{abstract}
The vestibular and ototoxic effects of the aminoglycoside antibiotics (streptomycin, gentamycin, kanamycin, tobramycin, neomycin) are well known; streptomycin, in particular, has been found to cause irreversible, profound, high frequency sensorineural deafness in hypersensitive persons. Aminoglycoside ototoxicity occurs both sporadically and within families and has been associated with a mitochondrial DNA (mtDNA) 1555A to $G$ point mutation in the $12 S$ ribosomal RNA gene. We report on the molecular analysis of a South African family with streptomycin induced sensorineural deafness in which we have found transmission of this same predisposing mutation. It is now possible to identify people who are at risk of hearing loss if treated with aminoglycosides in the future and to counsel them accordingly. In view of the fact that aminoglycoside antibiotics remain in widespread use for the treatment of infections, in particular for tuberculosis, which is currently of epidemic proportions in South Africa, this finding has important implications for the family concerned. In addition, other South African families may potentially be at risk if they carry the same mutation.

(F Med Genet 1997;34:904-906)
\end{abstract}

Keywords: deafness; mitochondria; ototoxicity; streptomycin

During a large scale investigation of genetic hearing loss in South Africa in 1982, ${ }^{1}$ a family was encountered in which several relatives had developed sensorineural hearing loss following the administration of streptomycin, in conventional doses, during the routine treatment of tuberculosis (TB). ${ }^{2}$ At that time it seemed probable that the family had a genetically determined susceptibility to ototoxicity and pedigree data were interpreted as being consistent with "irregular autosomal dominant inheritance". ${ }^{2}$ It has subsequently been recognised that familial aminoglycoside induced deafness may be transmitted by mitochondrial inheritance ${ }^{3-7}$ and it then became apparent that this mechanism could explain the distribution of affected persons in the South African family.

Following the reports of the identification of a mtDNA $A$ to $G$ point mutation at position 1555 in the $12 \mathrm{~S}$ ribosomal RNA gene in three Chinese $^{4}$ and two Japanese kindreds ${ }^{7}$ with anti- biotic induced ototoxicity, we have now reassessed the South African family with possible maternal inheritance of sensorineural deafness and have updated the pedigree. Molecular investigations were undertaken in order to search for the presence of the same mutation in the South African kindred.

\section{Investigations, subjects, and methods}

The family, which was of mixed ancestry (San, Khoi-Khoi, European, Madagascan, West African, and Javanese origin), lived in a small coastal town approximately 150 miles to the east of Cape Town. They initially came to the attention of the Department of Human Genetics in 1982 when they presented with a history of development of deafness following treatment for pulmonary tuberculosis. Eight family members had developed hearing loss (three males and five females aged between 6 and 49 years), and they were all admitted to Groote Schuur Hospital, Cape Town for investigation and otological management. At this stage the sensorineural nature of the deafness was determined and cochlear involvement was confirmed. Other potential aetiological factors were excluded.

In 1993, the extended family was revisited at home by a medical geneticist (JCG). The pedigree was updated and every family member was examined. The deafness was unchanged in the original eight affected persons who had been studied in 1982, but a further three adults (two males and one female), who had subsequently received antituberculous therapy, had also become deaf. In addition, a new generation of children had been born, among whom were potential recipients of the mutation. The updated pedigree is shown in fig 1 .

All 11 subjects with hearing impairment had received streptomycin therapy in standard doses and had subsequently developed deafness. Of these 11 , only nine persons were included in the molecular study, as two (III.51, III.52) declined to donate a blood sample for investigation. A total of 18 family members gave informed consent for the molecular study and the blood samples were collected in EDTA anticoagulant tubes for DNA extraction, using the Genomix Blood Scale Up Kit (Supplied by Promolab Pty Ltd T/A Separations). Blood specimens were also obtained from 20 unrelated unaffected subjects from the same population group in order to provide controls for the molecular study. mtDNA from one affected (deaf) person (III.42) in the family was initially restricted with BsmAI and then sequenced in 


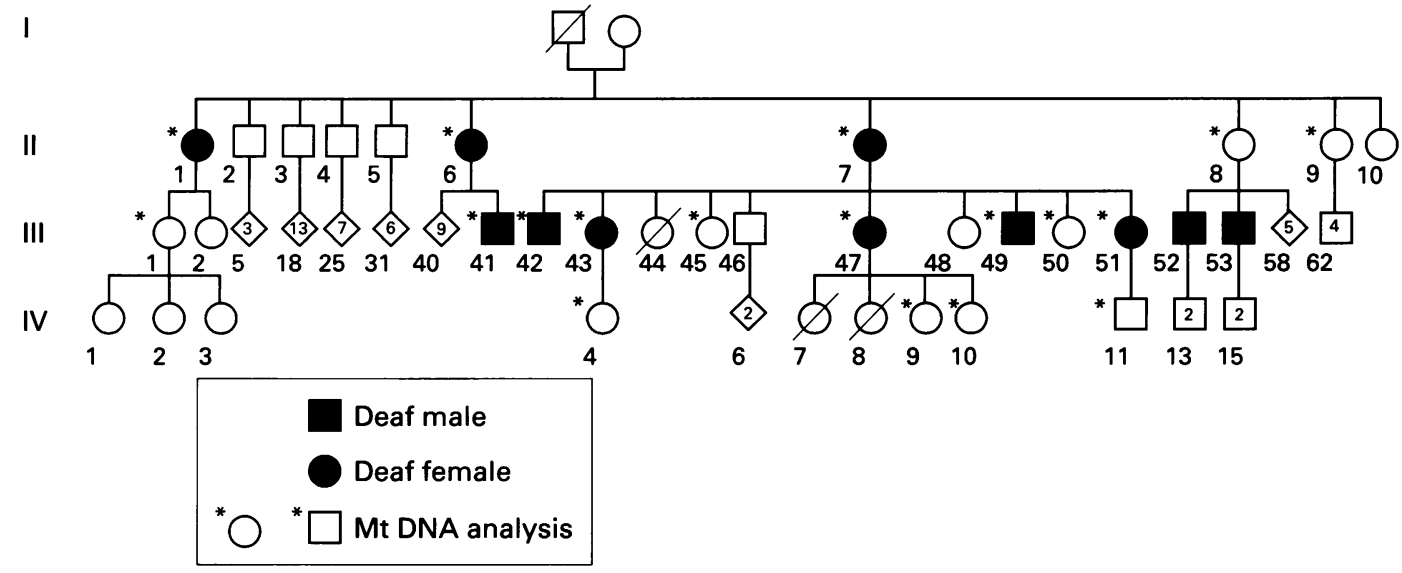

Figure 1 Pedigree of the affected family showing maternal pattern of inheritance.

order to search for the mutation. BsmAI restriction analysis was then undertaken in the rest of the family and in the controls.

\section{PCR REACTIONS}

mtDNA was amplified in a $50 \mu$ l reaction volume containing $1 \mu \mathrm{g}$ genomic DNA, 50 pmol of each primer, $50 \mathrm{mmol} / 1 \mathrm{KCl}, 10$ $\mathrm{mmol} / 1$ Tris- $\mathrm{HCl}, \mathrm{pH} 8.3,1.5 \mathrm{mmol} / 1 \mathrm{MgCl}_{2}$, $200 \mu \mathrm{mol} / 1$ each dATP, dGTP, dTTP, dCTP, and 1 unit of $T a q$ polymerase (BRL), overlaid with paraffin, with an initial three minutes denaturation at $95^{\circ} \mathrm{C}$, followed by 25 cycles of $95^{\circ} \mathrm{C}$ for 30 seconds, $60^{\circ} \mathrm{C}$ for 20 seconds in a Techne DNA thermal cycler. An $8 \mu$ aliquot of the amplified PCR product was added to $1 \times$ volume of the appropriate buffer supplied by the manufacturer, together with BSA (100 $\mu \mathrm{g} / \mathrm{ml}$ ) and 10 units of the enzyme BsmAI (New England Biolabs). The reaction was overlaid with a drop of mineral oil and incubated for one hour at $55^{\circ} \mathrm{C}$ and the digested DNA fragment was then run on a $4 \%$ agarose gel for one
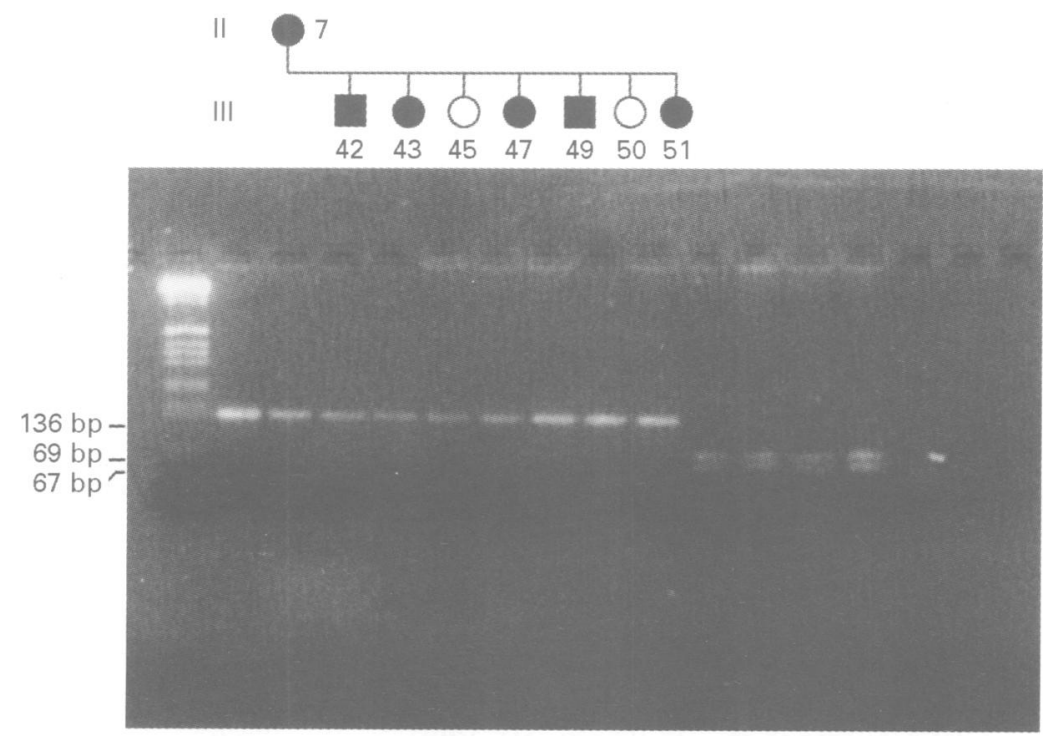

Figure 2 BsmAI restriction digest. Lane 1: $1 \mathrm{~kb}$ molecular weight marker. Lane 2: unrestricted control. Lanes 3 to 10: selected members of the South African family. Pedigree details are shown above each lane and correspond to those in fig 1 . A single 136 bp band is shown representing loss of the BsmAI restriction site where each person is homoplasmic for the $1555 \mathrm{~A}$ to $\mathrm{G}$ mutation. Lanes 11 to $14:$ BsmAI has cut at the wild type 1555 locus in four control subjects resulting in two smaller bands ( $69 \mathrm{bp}$ and $67 \mathrm{bp}$ ). hour. Two fragments ( $69 \mathrm{bp}$ and $67 \mathrm{bp}$ ) were identified in all control samples and a single $136 \mathrm{bp}$ PCR product, representing the uncut PCR product as a result of the $1555 \mathrm{~A}$ to $\mathrm{G}$ mutation, was identified in the family members using primers $\mathrm{H} 1.48$ and $\mathrm{H} 1.60$.

\section{PCR SEQUENCING}

The PCR product was purified from low melting point agarose gels (GeneLine LMP agarose, Beckman Instruments) with Promega's Magic Prep kit and sequenced, using primer $1.60,{ }^{7}$ with the New England Biolabs cycle sequencing kit, using [35S]dATP (NEN/ Dupont).

\section{Results (table 1)}

The presence of a mtDNA mutation in subject III.42 was shown by loss of the BsmAI restriction site and then confirmed as a $1555 \mathrm{~A}$ to $\mathrm{G}$ base change by sequencing. The remaining 17 family members studied all had the mutation, as was shown by the loss of the BsmAI restriction site in all instances. In the mtDNA from the 20 subjects in the control study, the BsmAI restriction site was consistently intact, as was observed by the formation of two bands following PCR amplification, BsmAI cleavage, and agarose gel electrophoresis, indicating the presence of the normal mtDNA sequence at the 1555 position in these persons (fig 2).

Table 1 Summary of results

\begin{tabular}{|c|c|c|c|}
\hline $\begin{array}{l}\text { Patient } \\
\text { (Pedigree No) }\end{array}$ & $\begin{array}{l}\text { Streptomycin } \\
\text { therapy }\end{array}$ & Deaf & $\begin{array}{l}1555 \mathrm{~A} \text { to } \\
G \text { mutation }\end{array}$ \\
\hline II. 1 & + & + & + \\
\hline II. 6 & + & + & + \\
\hline II. 7 & + & + & + \\
\hline II. 8 & - & - & + \\
\hline II. 9 & - & - & + \\
\hline III.1 & - & - & + \\
\hline III.41 & + & + & + \\
\hline III. 42 & + & + & + \\
\hline III.43 & + & + & + \\
\hline III. 45 & - & - & + \\
\hline III. 47 & + & + & + \\
\hline III.49 & + & + & + \\
\hline III.50 & ? & - & + \\
\hline III.51 & + & + & + \\
\hline IV.4 & - & - & + \\
\hline IV.9 & - & - & + \\
\hline IV.10 & - & - & + \\
\hline IV.11 & - & - & + \\
\hline III. $52^{\star}$ & + & + & $?$ \\
\hline III.53* & + & + & $?$ \\
\hline
\end{tabular}

$\star^{\star}$ Not included in DNA study. 


\section{Discussion}

Our results show that deafness in this family can be attributed to the administration of streptomycin in the presence of the $1555 \mathrm{~A}$ to $\mathrm{G}$ mtDNA mutation. This mutation has already been established in a number of subjects and pedigrees with aminoglycoside induced deafness and is thought to cause ototoxicity through the increased binding of streptomycin to the mitochondrial ribosome. ${ }^{78}$ The $1555 \mathrm{~A}$ to $G$ mutation has additionally been found in a family from Israel ${ }^{4}$ and Zaire, ${ }^{9}$ in which it was associated with non-syndromic deafness, occurring in a matrilinear pattern, in the absence of exposure to aminoglycosides. Deafness in these families is thought to be the result of the coinheritance of the mutation with a specific nuclear factor. ${ }^{4}$

The DNA in the study of the South African kindred was taken from nine deaf persons and from nine family members with normal hearing, all of whom were considered to be potential mtDNA mutation carriers by virtue of the fact that they were either the sibs or children of an affected mother or the mothers of affected members of the family. The $1555 \mathrm{~A}$ to $G$ transition was found in all of the 18 family members investigated, in deaf and hearing persons alike, and it was shown to be homoplasmic in blood.

In contrast, the mutation was not found in 20 unrelated controls from the same general population, and investigators studying other populations have made similar observations. $^{49}$ These control studies ${ }^{4910}$ indicate that the $1555 \mathrm{~A}$ to $\mathrm{G}$ base change is rare. This is supported by the fact that the transition has not been found in any kindreds other than those with deafness, even though, alone, it appears to exert no adverse effects.

The 1555A to $G$ mutation has been shown to result in deafness in the presence of aminoglycosides and of the nine family members who were carriers of the mutation but had retained normal hearing, eight had not received streptomycin therapy. One subject (III.50), however, had previously been documented as having received antituberculous therapy in an earlier report. ${ }^{2}$ If she had received streptomycin, we would have expected her to become deaf and it is surprising that she did not. On further investigation we have been unable to obtain firm evidence that she either took the drug or was compliant with her TB therapy and it is possible that, in actual fact, she never received any streptomycin. It seems reasonable, therefore, to assume that she will remain at risk, together with other mutation carriers in the family, from any aminoglycoside therapy in the future.

The maternal inheritance pattern of $\mathrm{mtDNA}$ is reflected by the transmission of the $1555 \mathrm{~A}$ to $G$ mutation in this family and the occurrence of deafness in the pedigree is consistent with mitochondrial inheritance. The close association of the aminoglycoside induced deafness trait with a rare mtDNA mutation provides further support for a causal relationship between the $1555 \mathrm{~A}$ to $\mathrm{G}$ mutation and deafness. There has been one other report of the $1555 \mathrm{~A}$ to $\mathrm{G}$ mutation on the African continent'; however, it has occurred on a mtDNA haplotype quite divergent from the South African pedigree, and thus it is likely that these two African pedigrees represent two independent mutations to $1555 \mathrm{G}^{10}$ The large mtDNA divergence that has been observed between $1555 \mathrm{G}$ pedigrees, in contrast to the small mtDNA divergence observed between mtDNA genomes bearing neutral mutations, is consistent with a model that the spread of the rare, deleterious $1555 \mathrm{G}$ mutation has been limited by negative Darwinian seletion. ${ }^{10}$

Aminoglycoside induced profound hearing loss is a serious handicap and the recognition that a propensity to ototoxic deafness can be transmitted by a mitochondrial mechanism has important implications for affected persons and their families. In the South African family, it can be inferred from the pattern of mitochondrial inheritance that there are several children in the kindred who are likely to have inherited the mutation from their mother. As the frequency of tuberculosis is increasing in South Africa, there is a real possibility that these children may be infected at some stage in the future. If this occurs, information concerning their status with respect to the mtDNA mutation and their risks of aminoglycoside toxicity will be crucial if antituberculous or other anti-infective therapy is required.

This study was supported by grants from the Medical Research Council of South Africa, the Mauerberger Foundation, the Harry Crossley Foundation, and the University of Cape Town Staff Research Fund.

1 Sellars S, Beighton P. Childhood deafness in Southern Africa: an aetiological survey of 3064 deaf children. $\mathcal{F}$ Laryngol Otol 1983;97:885-9.

2 Viljoen DL, Sellars SL, Beighton P. Familial aggregation of streptomycin ototoxicity: autosomal dominant inheritance? streptomycin ototoxicity: autoso

$3 \mathrm{Hu} \mathrm{DN}$, Qiu WQ, Wu BT, et al. Genetic aspects of antibiotic induced deafness: mitochondrial inheritance. $\mathcal{F}$ Med Genet 1991;28:79-83.

4 Prezant TR, Agapian JV, Bohlman MC, et al. Mitochondrial Prezant TR, Agapian JV, Bohlman MC, et al. Mitochondrial ribosomal RNA mutation associated with both antibioticinduced ar $289-93$.

5 Higaski $K$. Unique inheritance of streptomycin-induced deafness. Clin Genet 1989;35:433-6.

6 Jaber $\mathrm{L}$, Shohat M, Bu X, et al. Sensorineural deafness inherited as a tissue-specific mitochondrial disorder. $₹ \mathrm{Med}$ Genet 1992;29:86-90.

7 Hutchin T, Haworth I, Higashi K, et al. A molecular basis for human hypersensitivity to aminoglycoside antibiotics. Nucleic Acids Res 1993;21:4174-9.

8 Cortopassi G, Hutchin T. A molecular and cellular hypothesis for aminoglycoside-induced deafness. Hearing $R e s$ 1994;78:27-30.

9 Matthijs G, Claes S, Longo-Mbenza B, Cassiman JJ. Non-syndromic deafness associated with a mutation and a polymorphism in the mitochondrial $12 S$ ribosomal RNA gene in a large Zairean pedigree. Eur f Hum Genet 1996;4: 46-51.

10 Hutchin TP, Cortopassi GA. Multiple origins of a mitochondrial mutation conferring deafness. Genetics 1997;145:771-6. 